\title{
Quality, Freedom and Equity: the Proposition of Educational Management in China
}

\author{
Ying Wang ${ }^{1}$
}

Received: 7 July 2016 / Accepted: 12 July 2016 /Published online: 23 August 2016

(C) Springer-Verlag Berlin Heidelberg 2016

Since the enactment of Dakar Programme in 2000, all of the countries have taken a series of measures to achieve the aim of universal education, and China, as the country with the largest population in the world, also makes every effort to popularize the universal education and to achieve the equity of education. After the many years' management, the educational field in China also has taken quite great development, especially in the aspect of popularizing the universal education, and we have taken great achievements, just like the quite huge and great developments in the economic field.

In July, 2015, according to the Progress of China in Implementing the Millennium Development Goals (20002015) which was issued jointly by the government of China and UN agencies in China, China has achieved the goal of realizing universal primary education by 2015 ahead of schedule: when the Chinese Government has progressed towards free compulsory education in a phased and planned way, the Chinese also has achieve the targets of universal 9-year compulsory education and basic elimination of illiteracy among the adolescents, and illiteracy rate among the adolescents has been below $1.0 \%$, and the net enrollment rate of primary school-age children has increased to $99.8 \%$. In the aspect of eliminating gender disparity, the difference in net enrollment rate between boys and girls has been eliminated, and the gap between boys and girls in the years of education they received was narrowed from 1.3 years in 2000 to 0.8 years in 2014. In

Responsible editor: Philippe Garrigues

Ying Wang

fanne_wong@whu.edu.cn

1 Institution of Educational Science, Wuhan University, NO. 299, Ba-Yi Rd, Luo-jia-shan,Wuchang, Wuhan, Hubei Province 430072, People's Republic of China
2014, there were 32.458 million girl students in secondary schools, accounting for $47.84 \%$ of the total number of students there, and 43.7196 million girl students in primary schools, accounting for $46.26 \%$ of the total number of students there. The ratio of boy to girl students in primary and secondary schools is basically consistent with the ratio of school-age children between boys and girls.

These glorious data remarked that Chinese education has attained the aim of "equity" and "popularization" in some extrinsic data and indexes, but these glorious outside data cannot hide the level of deep conflicts in the Chinese educational equity. In addition, with a decade of development, these extrinsic conflicts have become internal conflicts. Due to their concealment, these internal conflicts of equity will be tough to solve.

1. Educational equity and quality of education: how to ensure students in the poverty-stricken areas can enjoy highquality education? Quality of education is the final direction of the educational equity, and the quality of education in the poverty-stricken areas in China is still severe from the point of view of students' scholastic achievement and the state of teaching staff. College entrance examination is the largest academic proficiency test, and students get the qualification to enter the college through college entrance examination. For the students in the poverty-stricken areas, college entrance examination is the only way for them to change their fate. However, according to a study published in the Social Science in China, the probability of rural students entering the college is getting smaller, and it will be increasingly difficult for them to enter the college. In addition, the rate of rural students in the Chinese top universities is declining obviously ( $\mathrm{Li}$, 2012). The level of teaching staff and salary of teaching staff are important indexes identified by UNESCO 
(United Nations Educational Scientific and Cultural Organization) to measure the quality of education, and the problem of educational equity between urban and rural areas is still severe through observing these measurement indexes. According to a research, there still be huge gap between the urban and rural areas, concerning to the age and professional level of teachers. When it comes to the age structure of teaching staff, teachers who were more than 50 years old occupied $22.75 \%$ of total teachers in rural elementary school, while the teachers who were more than 50 years old only occupied $4.65 \%$ of the total numbers of teachers in the urban primary school; the problem of "aging" is severe in the teaching staff of the rural school; however, when it comes to the mid-aged teachers who are the dominant power in the teaching and development of schools, the rate of the mid-aged teachers among the total teachers is only $42.97 \%$ in the rural schools, which is far below than the rate, $72.67 \%$ in urban schools, and the problem of lacking of mid-aged teachers is severe; when it comes to the specialty and profession of teachers, the rate of the teachers with non-normal professional background among the total teachers in rural schools is $23.21 \%$, while the rate is only $9.03 \%$ in urban schools. What is more serious problem is that the salary of a substitute teacher is only $400 \mathrm{RMB}$, approximately equivalent to 65 dollars every month probably in some poverty-stricken areas in western China, and such a level of salary cannot meet the needs of teachers' personal life; thus, many rural teachers not only need teach students in school but also must participate in agricultural production after school, which no doubt will lead to the declination of quality of education. Either the severe form of teaching staff or the depression of the rural students in the statelevel test shows the negative effects from the "low-level fairness", and the problem is also one of the problems the management of education in China faced with.

2. Education equity and education freedom: the diversity of people determines that education need satisfies different students' personalized needs of study and development. However, in order to pursue the equity among regions and equity between urban and rural, a large-scale activity of "construction of standard school" and "platform of "education cloud" occurred to the whole nation. The former, "construction of standard school", has solved the "equity" of school building exterior-all of the schools have been built with the similar exteriors, and even all of the schools have been built according to the same architectural drawings. The latter, "platform of "education cloud", emphasizes the schools in rural and poor areas can through the way of "education cloud" to share and use the curriculum resource made by the teachers in the urban schools, which will lead to the exterior equity of the teaching content.
However, does it mean educational equity to teach the same courses using the same teaching methods? Does the "uniformization" deprive students' right to choose the curriculum resource and teaching methods which are suitable for their life background? Does it lead to deprive students' right to choose their courses by themselves? Must people give up their some parts of freedom to attain to the equity? Whether should we pay attention to protect the freedom for individual to acquire knowledge when we proceed to these thriving constructions of standardization? All of them are also the severe problems that the Chinese educational management faced with.

In addition, except for the equity of school buildings' construction and the uniformization of the curriculum, the discussion about the educational freedom also exist in the game of the Chinese central ministry administrative institution and local ministry administrative institution. China is a great and consolidated uniformity of state, and the centralism of educational management system is always an obvious Chinese feature during many years. Faced with the central governmentdictated situation, every local authority is also in a complex game relationship, due to their respective appeals to the education interests. The game relationship not only exists in the different regions but also exists in the central and local levels. In just the past college entrance examination which is the largest nationwide examination held annually in China, contradictions in the game relationship are also exposed again in the college entrance examination.

Colleges and universities spread across the country in China, and they recruit students nationwide. However, the number of recruiting students of every college or university is different in the different provinces and cities nationwide. In all of the 31 provinces of China, there are eight different kinds of test papers with different test design members and teachers in different provinces, and it is difficult to measure all of the students in different provinces with a same index. Thus, the number of recruiting students of every college or university is not decided only by the entry scores in the country, and students cannot be only decided by the ranks which are based on their scores. Moreover, what is accepted by people widely is that the differences of educational quality and level among different regions and areas lead to the severe situation nowadays. Thus, when college A decides to recruit 1000 students nationwide, the 1000 quantity indexes are distributed among the 31 provinces, which means that if the province you lived attains more quantity indexes, you will have more possibility to be admitted to college $\mathrm{A}$. The design of the quantity index distribution system is also the best evidence of the game relationship among the central and local level. In May of this year, due to a policy of "decreasing the number of recruiting candidate for the college entrance examination", the parents of candidates for the college entrance examination in Hubei and 
Jiangsu broke out a sharp reaction and the policy also led to huge public discussion about education equity.

When it comes to the cause of the parents of candidates for the college entrance examination, let us review the whole story. Twelve provinces including Jiangsu province and Hubei province will relinquish 160,000 of quantity indexes of recruiting students to 10 provinces in the central and western regions of China, and Jiangsu province will relinquish 38,000 quantity indexes and Hubei will relinquish 40,000 quantity indexes. Because the Chinese government held the opinions that the backward economic development in central and western regions of China leads to the huge gap of education quality between the central and western regions and other regions of China, thus, the students in central and western regions should be given some preferential policy to go to college. However, Hubei province and Jiangsu province are also regarded as the provinces in which the competitions among candidates for the college entrance examination are intense. No doubt the policy has damaged the interests of candidates for the college entrance examination in Hubei province and Jiangsu province, and the parents of students in these two provinces worried about the acceptance rate at colleges would be declined and their kids would not be admitted to a college or would not be admitted to a good college. Meanwhile, they protested that the number of quantity indexes that be relinquished by the Beijing and Tianjin is quite less. At the same time, the central and western regions of China insisted that the number of undergraduate universities given to the central and western regions is too small and most of them are the technical colleges, and the given number of quantity indexes of key universities and "985" universities is smaller. And the contradiction has led to the long-term protestation of parents of candidates for the college entrance examination in Hubei province and Jiangsu province.

Such many facts about the education equity show that education equity, especially the education equity on the premise of education quality, has become the more important goal of development when China has been achieved popularization of the universal education as a whole. Meanwhile, the relationship between education equity and efficiency, the relationship between the education equity and freedom, and the relationship between education equity and excellence still need to be discussed and analyzed from the multiple perspectives in the process of operation. 